\title{
STRUCTURA PARAZITISMULUI LA ȘOARECELE SCURMĂTOR DIN ECOSISTEME FORESTIERE
}

\author{
Chihai Oleg, Erhan Dumitru, Rusu Ștefan, Tălămbuţă Nina', \\ Nistreanu Victoria, Larion Alina, Zamornea Maria, Melnic Galina
}

Institutul de Zoologie al Ministerului Educației, Culturii și Cercetării, Chișinău, R. Moldova

${ }^{1}$ Universitatea Liberă Internaţională din Moldova

E-mail: olegchihai@yahoo.com

https://doi.org/10.53937/9789975315975.35

\begin{abstract}
Bank vole (Myodes glareolus) is widely spread silvicolous species, inhabiting in woods, forest clearings, shrub vegetation, at forest edge, near ponds with abundant vegebtation. The parasite fauna is structured of 3 classes, 13 families, 14 genera and 15 species, of which $6.6 \%$ belong to class Trematoda, $46.7 \%$ to class Cestoda and $46.7 \%$ to class Nematoda. The results of the parasitological investigations show a prevalence of Plaghiorchis elegans of $13.8 \%$ and an average intensity of 3.8 ex, respectively with Mesocestoides lineatus larvae 14.0\%, 1.5 ex, Paranoplocephala omphaloides - 10.3\%, 2.7 ex, Rodentolipis straminea - 69.0\%, 3.0 ex, Hydatigera taeniaeformis larvae - 10.3\%, 1.0 ex, Catenotaenia cricetorum - 10.3\%, 2.7 ex, Skrewabinotaenia lobata - 3 ex, Taenia pisiformis - 13.7\%, 1.0 ex, Capillaria hepatica - 27.5\% and liver infestation is about 50.0\% (++), Syphacia stroma - 17.2\%, 94 ex, Syphacia obvelata - 24,1\%, 84, 9 ex, Heligmosomoides polygirus - 10,0\%, 5,3 ex, Strongyloides ratti - 6,9\%, 23,3 ex, Mastophorus muris - 17,2\%, 3, 6 ex and Trichocephalus muris $17.2 \%$, intensity 3.8 ex. The share of the Trematoda species is $6.6 \%$, in the Cestoda class $-46.7 \%$, and in the Nematoda class $-46.7 \%$. The massive abundance of foxes on large land surfaces, including ecological plasticity with tendency toward synantropization, are the primary factors in the formation, maintenance and spreading of parasitosis outbreaks in natural and anthropic ecosystems. The aim of the research is to study the diversity of parasite fauna in Myodes glareolus from forest ecosystems with specifying the parasite taxonomic structure and determining the degree of infestation.
\end{abstract}

Key words: parasites, prevalence, rodents.

\section{INTRODUCERE}

Parazitismul în ecosistemele naturale este considerat fenomen ecologic, reprezentând totodată o formă de relație interspecifică. Datorită di- 
versității legăturilor ecologice, paraziții reprezintă un factor important de reglare numerică a populațiilor de gazde și respectiv în funcționarea sistemelor parasit-gazdă $[8 ; 9]$.

Factorul antropic are o influență considerabilă asupra proceselor din natură, inclusiv asupra paraziților, care sunt componente esențiale ale biotei, iar ca rezultat se modificată biodiversitatea și statutul ecologic. În asemenea condiții unele specii de helminți pot avea importanță epidemiologică. Astfel, devine necesar monitoringul biodiversității și ecologiei asociațiilor de helminți la speciile de gazde din diferite arealuri [10].

Rozătoarele mici cauzează pagube considerabile producţiei agricole și sunt implicate în transmiterea agenţilor patogeni (virusuri, bacterii, paraziți) la om, animale domestice și sălbatice [5; $1 ; 6 ; 2$ ]. Monitorizarea parazitofaunei la rozătoarele mici cu precizarea rolului epidemiologic, prezintă o importanță majoră pentru prevenirea transmiterii agenților patogeni la om și animale, care sunt implicate în ciclurile evolutive ale paraziților.

Scopul cercetărilor vizează studiul diversităţii parazitofaunei la Myodes glareolus din ecosisteme forestiere cu specificarea structurii taxonomice și determinarea gradului de infestare.

\section{MATERIALE ȘI METODE}

Cercetările au fost efectuate în ecosistem forestier din Rezervaţia „Plaiul Fagului" la ecotonul de la liziera pădurii de pe malul iazului. Vegetația de subarboret este destul de densă, fiind constituită din exemplare tinere de stejar, carpen, frasin, lemn râios, alun și corn. Vegetația ierboasă este abundentă și densă, reprezentată de specii higrofile și de luncă. Ecosistemul este cu tendință de antropizare, deaorece reprezintă o zonă recreațională pentru vizitatori. Contactul direct sau indirect cu rozătoarele mici sălbatice, denotă un risc major de transmitere a agenților parazitari de la fauna sălbatică la animalele domestice și om. 
Șoarecele scurmător (Myodes glareolus) fiind o specie silvicolă se întâlnește în păduri luminoase (poiene), în sectoare cu subarboret și la lizieră, pe terenuri umede de la marginea bălților.

Rozătoarele mici au fost capturate pe viu, prin amplasarea a 100 de capcane la o distanța de 5 m una față de alta. Această metodologie este recomandată pentru biotopurile cu etajul subarboretului bine dezvoltat și strat ierbos abundent [4].

Cercetările parazitologice au fost realizate în laboratorul de Parazitologie și Helmintologie al Institutului de Zoologie. Rozătoarele colectate au fost eutanasiate cu soluție de Cloroformi pro narcosi. Acest remediu inhibă conductibilitatea la nivelul centrelor cardiace, provocând instantaneu moartea ușoară fără suferință. Investigațiile de laborator au fost efectuate prin disecţie totală a rozatoarelor și examen microscopic al sistemului muscular (muș. maseteri, muș. braţelor, muș. diafragmului), organelor interne (trahee, pulmoni, cord, limbă, esofag, stomac, intestin subţire, intestin gros, ficat, splină, rinichi, vezica urinară) pentru evaluarea indicilor parazitologici: prevalenţa (\%) și intensitatea medie (exemplare/animal). Gradul de infestare cu Capilaria hepatica a fost stabilit, prin estimarea volumetrică a porțiunii de ficat afectat (+ constituie $25,0 \%,++-50,0 \%,+++-75,0 \%$, ++++ - 100\%). Determinarea speciilor a fost efectuată după Рыжиков К., и Ap. [11; 12]. Rezultatele au fost prelucrate statistic în programul Excel.

\section{REZULTATE ȘI DISCUŢII}

Studiul parazitologic include examinarea a 29 specimene de Myodes glareolus din zona ecotonului de la liziera pădurii de pe malul iazului Rezervației "Plaiul Fagului".

Structura taxonomică a parazitofaunei, este încadrată în 3 clase, 13 familii, 14 genuri și 15 specii (tab.1). Cota speciilor din clasa Trematoda constituie 6,6\%, din clasa Cestoda - 46,7\%, iar din clasa Nematoda - 46,7\%. 
Tabelul 1. Structura taxonomică a parazitofaunei la Myodes glareolus

\begin{tabular}{|c|c|c|c|}
\hline Clasa & Familia & Specia & $\begin{array}{l}\text { Cota spe- } \\
\text { ciilor }\end{array}$ \\
\hline Trematoda & Plagiorchidae (Luhe, 1901) & Plagiorchis elegans (Rudolphi, 1802) & $6,6 \%$ \\
\hline \multirow{7}{*}{ Cestoda } & \multirow{2}{*}{$\begin{array}{l}\text { Catenotaeniidae Spassky, } \\
1950\end{array}$} & Skrjabinotaenia lobata (Baer, 1925) & \multirow{7}{*}{$46,7 \%$} \\
\hline & & $\begin{array}{l}\text { Catenotaenia cricetorum Kir- } \\
\text { shenblat, } 1949\end{array}$ & \\
\hline & \multirow{2}{*}{ Taeniidae (Ludwig, 1886) } & $\begin{array}{l}\text { Hydatigera taeniaeformis larvae } \\
\text { (Batsch, 1786) }\end{array}$ & \\
\hline & & $\begin{array}{l}\text { Taenia pisiformis larvae (Bloch, } \\
\text { 1780) }\end{array}$ & \\
\hline & $\begin{array}{l}\text { Mesocestoididae (Perrier, } \\
\text { 1897) }\end{array}$ & $\begin{array}{l}\text { Mesocestoides lineatus larvae (Go- } \\
\text { eze, 1782) }\end{array}$ & \\
\hline & $\begin{array}{l}\text { Anoplocephalidae (Cholod- } \\
\text { kowsky, 1902) }\end{array}$ & $\begin{array}{l}\text { Paranoplocephala omphaloides } \\
\text { (Herman, 1783) }\end{array}$ & \\
\hline & $\begin{array}{l}\text { Hymenolepididea (Ariola, } \\
\text { 1899) }\end{array}$ & $\begin{array}{l}\text { Rodentolepis straminea (Goeze, } \\
\text { 1782) }\end{array}$ & \\
\hline \multirow{7}{*}{ Nematoda } & \multirow{2}{*}{$\begin{array}{l}\text { Syphaciidae (Skrjabin et Schik- } \\
\text { hobalova, 1951) }\end{array}$} & Syphacia obvelata (Rudolphi, 1802) & \multirow{7}{*}{$46,7 \%$} \\
\hline & & Syphacia stroma (Linstow, 1884) & \\
\hline & $\begin{array}{l}\text { Capillariidae (Neveu-Lemaire, } \\
\text { 1936) }\end{array}$ & Capillaria hepatica (Bancroft, 1893) & \\
\hline & Trichocephalidae (Baird, 1853) & Trichocephalus muris (Scrank, 1788) & \\
\hline & Spiruridae (Oerley, 1885) & Mastophorus muris (Gmelin, 1790) & \\
\hline & Heligmosomidae (Cram, 1927) & $\begin{array}{l}\text { Heligmosomoides polygirus (Dujar- } \\
\text { din, 1845) }\end{array}$ & \\
\hline & $\begin{array}{l}\text { Strongyloididae (Chitwood et } \\
\text { Macintosh, 1934) }\end{array}$ & $\begin{array}{l}\text { Strongyloides ratti (Sandground, } \\
\text { 1925) }\end{array}$ & \\
\hline
\end{tabular}

Analizând gradul de infestare a rozătoarelor investigate după extindere și abundență numerică (tab. 2) am constatat că trematodul Plaghiorchis elegans este răspândit cu o prevalență de 13,8\% și intensitate medie de 3,8 ex./animal.

Din clasa Cestoda au fost evidențiate total 7 specii, inclusiv 4 specii cu parazitism imaginal și 3 specii cu parazitism larvar. Metacestodele sunt înregistrate cu o prevalență și intensitate medie pentru Hydatigera taenieformis larvae - 10,3\% și 1,0 ex./animal, pentru Taenia pisiformis larvae - 13,7\% și 1,0 ex., iar pentru Mesocestoides lineatus larvae - 14,0\% și 1,5 exemplare. Parazitismul imaginal cu cestode este reprezentat de Skrja- 
binotaenia lobata cu o prevalență de 10,3\% și intensitate medie de 3,0 ex., Paranoplocephala omphaloides - 10,3\% și 2,7 ex., iar Rodentolipis straminea - 69,0\% și 3,0 exemplare.

Gradul de răspândire a nematodelor în populația gazdei este estimat cu valori dominante pentru Capillaria hepatica $(27,5 \%)$ și Syphacia obvelata $(24,1 \%)$. O descreștere ușoară a prevalenței este observată la Syphacia stroma (17,2\%), Mastophorus muris (17,2\%) și Trichocephalus muris (17,2\%), fiind urmată de Heligmosomoides polygirus (10,0\%) și Strongyloides ratti (6,9\%). După abundență numerică în populația nematodelor poziție dominantă ocupă Syphacia stroma cu intensitate medie de 94 ex., fiind urmată de Syphacia obvelata (84,9 ex.), apoi Strongyloides ratti (23,3 ex.), Heligmosomoides polygirus (5,3 ex.), Trichocephalus muris (3,8 ex.), Mastophorus muris (3,6 ex.) și Capillaria hepatica cu gradul de afectare a ficatului estimat volumetric cca. 50,0\% (++).

Tabelul 2. Gradul de infestare la Myodes glareolus

\begin{tabular}{|l|l|l|l|}
\hline Nr. & Specia & Prevalenţa, $\%$ & Intensitatea, ex. \\
\hline 1 & Plagiorchis elegans & 13,8 & 3,8 \\
\hline 2 & Skrjabinotaenia lobata & 10,3 & 3,0 \\
\hline 3 & Catenotaenia cricetorum & 10,3 & 2,7 \\
\hline 4 & Paranoplocephala omphaloides & 10,3 & 1,0 \\
\hline 5 & Rodentolepis straminea & 69,0 & 3,0 \\
\hline 6 & Hydatigera taeniaeformis larvae & 10,3 & 1,0 \\
\hline 7 & Taenia pisiformis larvae & 13,7 & 1,0 \\
\hline 8 & Mesocestoides lineatus larvae & 14,0 & 1,5 \\
\hline 9 & Syphacia obvelata & 24,1 & 84,9 \\
\hline 10 & Syphacia stroma & 17,2 & 94,0 \\
\hline 11 & Heligmosomoides polygirus & 10,0 & 5,3 \\
\hline 12 & Mastophorus muris & 17,2 & 3,6 \\
\hline 13 & Strongyloides ratti & 6,9 & 23,3 \\
\hline 14 & Trichcephalus muris & 17,2 & 3,8 \\
\hline 15 & Capillaria hepatica & 27,5 & ++ \\
\hline
\end{tabular}

Comparativ cu perioada anilor 1958-1968 rezultatele obținute denotă o sporire esențială a indicilor invazionali [7]. Acest fapt se datorează, 
probabil, suprafețelor mari de pârloage, în care se mențin condiții favorabile pentru dezvoltarea rozătoarelor mici. La acești factori se adăugă creșterea considerabilă a numărului de vulpi (de 10 ori), în hrana cărora predomină rozătoarele (70\%), care răspândesc formele parazitare, poluând diferite arealuri.

Majorarea indicilor invazionali la M. glareolus se datorează și faptului că unele specii din clasa Nematoda sunt geohelminți (Heligmosomoides polygirus, Trichocephalus muris, Capillaria hepatica, Syphacia stroma, Syphacia obvelata) și evoluează fără gazde intermediare. Larvele și ouăle fertilizate sunt rezistente la factorii climatici, trăiesc liber în mediul ambiant cu dezvoltări succesive și sunt vehiculate de răpitori (Vulpes vulpes) care consumă rozătoarele infestate. Biohelminții (Mesocestoides lineatus larvae, Hydatigera taeniaeformis larvae, Taenia pisiformis larvae) au drept gazdă definitivă vulpea, care reprezintă factorul principal de răspândire a formelor invazionale (oncosfere, proglote ovigere) în mediul ambiant. Sectorul de activitate individuală a unei vulpi este de cca 500 ha, dar în Republica Moldova efectivul de vulpi depășește 10 indivizi la 1000 ha [3]. Abundența masivă a vulpilor pe suprafețe mari de terenuri, inclusiv plasticitatea ecologică cu tendință de sinantropizare, sunt factorii primordiali în formarea, menținerea și răspândirea focarelor de parazitoze din ecosistemele naturale și antropizate.

Datele obţinute denotă riscul de poluare parazitară a zonei de interferenţă dintre ecosistemele naturale și antropizate, iar ca rezultat are loc transmiterea formelor invazive de la animalele sălbatice la cele domestice, inclusiv la om. Totodată, rozătoarele ca componentă a lanţului trofic al răpitorilor mai mari, iar aceștia la rândul lor ca vectori ai formelor infestante libere în mediul ambiant, asigură stabilitatea funcţională a sistemelor parazit-gazdă în cadrul biocenozelor.

\section{CONCLUZII}

1. Structura taxonomică a parazitofaunei la Myodes glareolus, constă din 3 clase, 13 familii, 14 genuri și 15 specii. Cota speciilor din 
clasa Trematoda constituie 6,6\%, din clasa Cestoda -46,7\%, iar din clasa Nematoda - 46,7\%.

2. Structura diversității pune în evidență o prevalență cu Plaghiorchis elegans de 13,8\%, cu Mesocestoides lineatus larvae - 14,0\%, Paranoplocephala omphaloides - 10,3, Rodentolipis straminea - 69,0\%, Hydatigera taeniaeformis larvae - 10,3\%, Catenotaenia cricetorum - 10,3\%, Skrjabinotaenia lobata - 10,3\%, Taenia pisiformis larvae - 13,7\%, Capillaria hepatica - 27,5\%, Syphacia stroma - 17,2\%, Syphacia obvelata - 24,1\%, Heligmosomoides polygirus - 10,0\%, Strongyloides ratti - 6,9\%, Mastophorus muris - 17,2\% și Trichocephalus muris $-17,2 \%$.

3. Rezultatele obținute relevă riscul de poluare parazitară a zonei de interferență dintre ecosistemele naturale și antropizate, facilitând transmiterea formelor invazionale de la animale sălbatice celor domestice, inclusiv omului.

Investigațiile au fost efectuate în cadrul proiectelor fundamentale 15.817.02.12F și 15.187.0211F.

\section{BIBLIOGRAFIE}

1. Durden L.A, H. R. Oliver J.H., et al. Rodents ecto-parasites from two locations in northwestern Florida. In. Vec. Ecol. 2000. nr 25. P. 222-228.

2. Malsawmtluangi $C$., Tandon V. Helminth parasite spectrum in rodent hosts from bamboo growing areas of Mizoram, north-east India. J Parasitol Dis. Nr. 33(1-2). 2009. P.28-35.

3. Munteanu Andrei, Lozan Mina. Lumea animală a Moldovei. Vol. IV Mamifere. Editura "Știința", 2004. P. 74-75.

4. Pelikan J., Zejda J., Holisova V. Influence of trap spacing on the catch size of dominasnt species of small forest mammals. In. Zool Listy. nr 24 (4). 1975. P. 313-324.

5. Singh Y.P, Gangwar S, Kumar D, et al. Rodent pests and their management in the northeastern hill region. In. Research bulletin. Nr. 37, ICAR research 
complex for NEH region, Barapani, Meghalaya. 1995. P. 35.

6. Stojcevic D, Mihaljevic Z, Marinculic A. Parasitological survey of rats in rural regions of Croatia. Veterinární Medicína. nr. 49 (3). 2004. P. 70-74.

7. АнАрейко О. Ф. Паразиты млекопитающих Молдавии. Кишинев: Штиинца, 1973. 185 с.

8. Беклемишев В.Н. Биоценотические основы сравнительной паразитологии. М. Наука. 1970. 501 с.

9. Контримавичус В.^. Паразитарные системы и их значение в популяционной биологии гельминтов. В. Паразитология. 1982. Т. 16. № 1-4. С. 197-215.

10. Ромашова Н.Б. Экология и биоразнообразие гельминтов мышевидных грызунов в условиях островных лесов центрального Черноземья. Аиссертация кандидата биологических наук. Воронеж. 2003. 212 с.

11. Рыжиков К.М., Гвоздев Е.В., Токобаев М.М., и др. Определитель гельминтов грызунов фауны СССР. Цестоды и трематоды. М., 1978. $232 \mathrm{c}$.

12. Рыжиков К.М., Гвоздев Е.В., Токобаев М.М., и др. Определитель гельминтов грызунов фауны СССР. Нематоды и акантоцефалы. М., 1979. 272 c. 